\title{
Modeling, structural and cfd analysis of mobile robot for banana cultivation
}

DOI:10.36909/jer.ICMMM.12443

\section{S. Baskaran*, Dr.T.Ramesh Kumar}

Department of Mechanical Engineering, Bannari Amman Institute of Technology, Tamil Nadu, 638 401,India

*Email: baski.349@gmail.com; Corresponding Author

\begin{abstract}
The banana plantation is a popular cash crop in southern parts of India. Globally, India ranks first in banana production by producing about 14 million metric tons annually. Cultivation of which involves humongous manual tasks with moderate difficulty, often the tasks are accompanied by considerable spending towards accomplishing those tasks. More often than not it affects the earning prospects of the farmer thus, succumbing to a great loss of investment. A valid solution to this problem from the technological perspective is to provide low-cost automation for the hectic tasks in banana cultivation. Through this work, a baby step towards addressing the issues in banana cultivation is initiated. This paper deals with the design, structural, computational fluid dynamics simulation of an Agricultural field robot for aiding banana cultivation by producing a plantation hole for banana seedlings. The conceptualized idea is modeled in 3dimension using SolidWorks software with suitable dimensions, then by applying desired material properties to the individual components a static structural analysis is executed on the assembly. After the completion of structural analysis, subsequently, CFD analysis is carried out with an Ansys-Fluent workbench on the equivalent solid modal replica of the assembly modal, developed exclusively to analyze the wind effects.
\end{abstract}

Key words: Banana cultivation; field robot; computational fluid dynamics; ansys; 3dimension. 


\section{INTRODUCTION}

The use of robotics decreases the working load of individuals and frees the workers from tiresome - anti-creative activities which can be used more effectively. The purpose of this study is the design and analyze a mobile robot for planting pit activities. In mobile and stationary environments, the main chassis of the robot is designed to have optimum stability at all times. The mobile robot is designed to travel around the field with maintaining a required distance between holes and the diameter of pits. This robot embodies four wheels along with a drive motor mounted to each wheel to meet the high torque needed to manoeuvre through the agriculture field. Additionally, at the top of the wheel forks, four steppers are positioned in such a way to spin the wheels while approaching any turn. In the middle the double ball screw mechanism is provided, earth drills of various sizes can be attached in between them, this mechanism facilitates in elevating and lowering of earth drills. In order to improve working performance, the weight ratio of the robot to the payload had to be kept as low as possible.

It's a formidable task to develop a durable and modular mobile robot that can function in difficult environments. This paper presents a mobile robot for use in the military, recovery and manufacturing. Elevation constraint is the key restriction for robot development, but powerful pneumatic and hydraulic systems can solve this. The spiral lift was used for adjusting the mobile robot platform height. Spiral lifts are innovative simple equipment for high load lifting in industries. Authors build and analyze the robot with a spiral lift through customized CAD applications on researching many mobile robot mechanisms. (Shah R et al.,2012).

Differential drive robots often have a multitude of uses in the fields of defense, identification, in-house cleaning and many more. This paper intends to offer a clear and effective process by evading the physical difficulties of the actual universe. The logic of obstruction recognition using an ultrasonic sensor and Arduino Uno were developed through a prototype model, but it was very difficult to optimize the robot physically by experiments. Therefore, an identical simulation in MatLab is performed for simple optimization. It is presented with the kinematic 
equations for the operation of the 3D model in a MatLab tool-box by applying VR technology.(Anirudh Topiwala., 2016).

Intelligent ideas for autonomous agricultural vehicles, which could potentially lead to a new ecological paradigm to improve agriculture, were demonstrated by a robotic platform. The vehicle is fitted with row guidance and weed identification cameras. Four similar wheel assemblies, which have four steering mechanisms for propulsion, are used with a modular method. The platform control is achieved by means of electronic vehicles and a control system based on integrated controllers. The configuration of the controller causes the front and rear of the vehicle to follow a prefixed path, causing the car to remain balanced with the path. The logic of the controller is explained and the results of field tests are discussed. (Bak T et al., 2004).

In the field of agriculture, conventional approaches are still followed, in the context of today's technology farming is highly irrelevant, a strong automation market is in place for different fields of cultivation. An effort is made in this paper to automate one of the agricultural fields that monitor crop output. The primary goal of this paper is intended to track crop growth with modern instruments.(Praveen D. Jadhav et al., 2016).

This manuscript introduces the concept of ROBI, a mobile prototype manipulator built for agricultural uses following the demands of low-cost, low-weight, simplicity, versatility, and modularity. It explains the mechanical architecture and specification of the key elements, including sensors and motors, of the motion control system. This is also derived from the kinematic and interactive versions of the robot, to facilitate the conception and the preliminary evaluation of the design options in the trajectory tracking system. Finally, the feasibility of those choices is seen by two simulations, one directly connected to a true direction in an agricultural area. (Bascetta L., et al,2017). 
This paper deals with the mechatronic architecture of a four-wheel-drive / steer robot, the MARIO as a non-holonomic omnidirectional robot. The use of numerous software methods for the rapid creation of the robot chassis and the other mechanical components was aided by a revolutionary integral use of CAD / CAM / CAE and RP. The masterpieces are created with machining and 3D printing in the workshop. In addition, a Robot Operating System (ROS) was used for modeling, simulating and designing software control framework. (Sharifi M et al., 2016).

It is introduced in this document, a method of handling heavy materials by agricultural robots. The validity of the structural and control mechanisms are verified by studies in open field watermelon harvesting. An specific design procedures have been verified, and three main design techniques have been explained, for both structural and control systems.(Sakai $\mathrm{S}$ et al.,2008).

Parameters such as resistance, volume and versatility for use in precision agriculture demanded clear research and development of automation techniques. It stresses the use of remote sensing methodologies used along with a GIS. This is primarily meant for the European Union, the USA and Japan in implementing Agricultural Mobile Robots. Research is required in Brazil to build robotic platforms as the basis for semi-autonomous and autonomous systems of navigation. The goal of this research is to explain the project for a field experimental data collection framework along with the study of the spatial variability. (Tabile R.A et al., 2011) 


\section{CONCEPTUALIZATION THROUGH 3D MODEL}

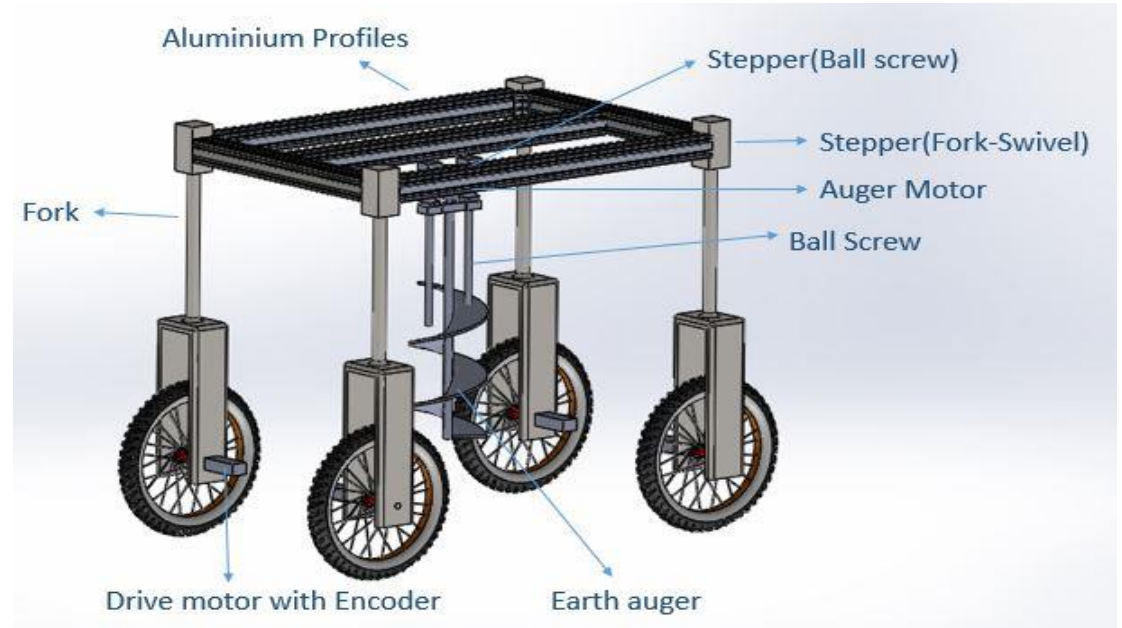

\section{Method of operation}

Figure 1 Conceptual Model of Field Robot

Fig.1 depicts the conceptual model of a mobile robot. Design choices were made considering production cost, strength to weight ratio and modularity. Operation wise this robot is teleoperated with remote, as per the user instructions it would move around the field to locate the point on which it makes a hole. Again the auger can be lowered to required depth, on reaching the required depth the auger motor starts rotating for producing hole. Once the holing operation is performed the auger reverts back to original position.

Figure $2 \mathrm{~A}$

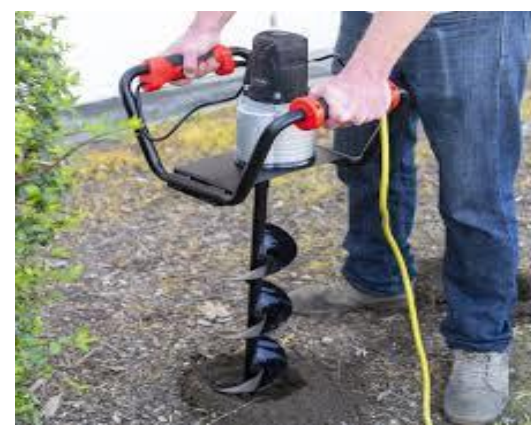

view of manual plantation

hole production process 


\section{COMPONENTS AND SUBSYSTEM}

The ideal requirements for the field robot were: Traction, Steering, Manipulator, End effector, Chassis or frame, Motors and power supply

\section{Chassis or frame}

The architecture must be able to function in an unstructured world. Therefore, $60 \times 60$ crosssection aluminium profiles are used. Compared to commercial alternatives, it is lightweight and modular, with the potential to insert sensors and actuators. Four wheels with the length parallel to the crop line is selected for the vehicle, which have been mounted on each corner of a rectangular frame to provide outstanding stability. The system is designed to be implemented in optimum conditions with telescopic bars. The system is completed by the steering, propulsion and central box. As the operating speed of the mobile robot is limited, a suspension is not necessary.

\section{Traction}

Wheels and tracks are the most traditional traction systems. The track structure improves the load distribution on the surface, decreases compaction and distortion of the soil substantially as well as increases the traction potential in loose soils. Tracks are popular in large devices or those that need high performance, but have high production and maintenance costs. Wheeled solutions are economical and fulfill the needs of this initiative, based on the low requirement for traction and power. In this initiative, a four wheel system was introduced to improve the car's ability to pull under unfavorable circumstances by means of the individual traction of each wheel.

\section{Steering}

Differential steering, integral steering and wheel steering are the part of steering systems. The disparity in the rotation speed of the right and left wheels or track functions as differential steering. 
The synchronization is quick in differential steering but the downside is that the vehicle slips sideways as it revolves around a vertical axis, which means unnecessary energy is wasted. System under discussion employs a mechanism by which each wheels turn individually by means of stepper motor mounted above its fork at times when the turn approaches, it is also programmed to turn 90deg from the fixed axis to achieve switching between the planned paths.

\section{Manipulator and End Effector}

Manipulator is device which is built around the mobile platform to assist the end effectors to accomplish its intended functionalities. In this robot ball screw mechanism based manipulator is used to raise and lower the earth auger drill, in the course of moving earth auger drill is raised while performing holing operation it is lowered again. Earth auger drill is an end effector which is used to produce a hole as per its diameter.

\section{Drafting}

(a)
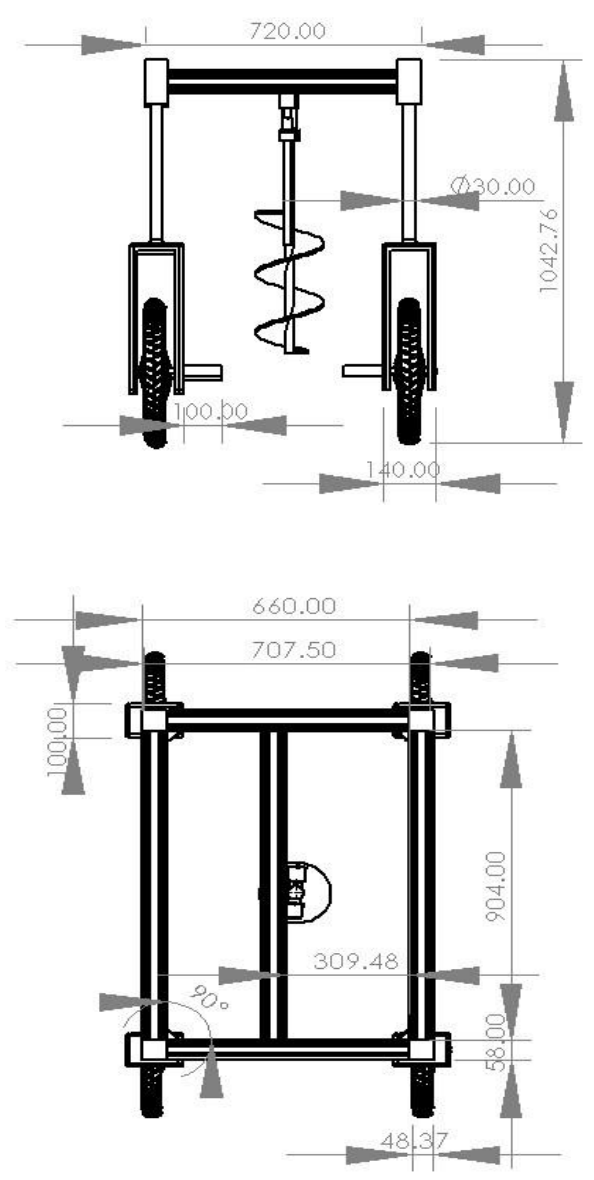

(b)

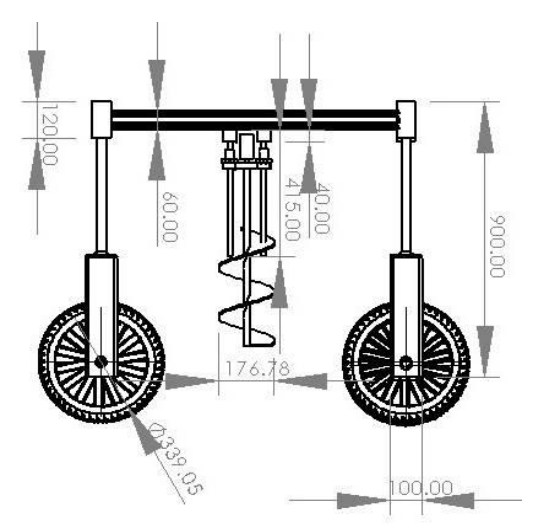

(c)

Figure 3 Orthographic Views (a) Front (b) Side (c) Top 


\section{DESIGN VERIFICATION WITH CAE ANALYSIS}

The Agricultural mobile robot mechanical system has been developed using the technique of virtual prototyping. The use of CAD and CAE applications is essential to verify a concept before committing to a physical unit. This is achieved by the development of geometric forms (parts) formed by the machine. CAE software can check assembly or individual parts for the various stresses that the system can face in the real world. The outcomes of a mobile robot in static simulation are discussed as well, for instance stress, total / directional deformation, equivalent stress, normal stress and strain.

\section{Structural Analysis}

Structural analysis is carried out on the assembly for two criteria's i) Standard earth gravity ii) Forces with magnitude. The structural analysis has been done using Ansys workbench 15, the FEA virtual object is composed of nodes and elements as provided in Table1. As the total volume of the robot assembly is composed of different individual components the standard material properties existing for those components is assigned. Fork, motors housing and earth auger is assigned with a material property of plain carbon steel. Ball screw and wheel rim is assigned with the material property of stainless steel. Tire is assigned with the material property of rubber. Aluminium profiles and angle brackets supporting profiles are assigned with a property of aluminium 6060-T5.

The properties of the virtual object after material assignment becomes as provided in the table1. For a linear static structural analysis, the displacements $\{\mathrm{x}\}$ are solved from the matrix equation below

$[\mathrm{K}]\{\mathrm{x}\}=\{\mathrm{F}\}$

$[\mathrm{K}]$ is constant and $\{\mathrm{F}\}$ is statically applied load 
Table 1 Properties of the virtual Model

\begin{tabular}{|l|l|}
\hline Volume & $2.2734 \mathrm{e}+007 \mathrm{~mm}^{3}$ \\
\hline Mass & $104.28 \mathrm{~kg}$ \\
\hline Scale Factor Value & 1. \\
\hline Bodies & 42 \\
\hline Nodes & 778057 \\
\hline Elements & 388899 \\
\hline
\end{tabular}

Table 2 Material Properties of Assignment Materials

\begin{tabular}{|l|l|l|l|l|}
\hline Material Name & Aluminium 6063 T5 & Stainless steel & Plain carbon steel & Rubber \\
\hline Density & $2.7 \mathrm{e}-006 \mathrm{~kg} / \mathrm{mm}^{3}$ & $\begin{array}{l}8.027 \mathrm{e}-006 \\
\mathrm{~kg} / \mathrm{mm}^{3}\end{array}$ & $7.8 \mathrm{e}-006 \mathrm{~kg} / \mathrm{mm}^{3}$ & $\begin{array}{l}9.6 \mathrm{e}-007 \\
\mathrm{~kg} / \mathrm{mm}^{3}\end{array}$ \\
\hline $\begin{array}{l}\text { Young's } \\
\text { Modulus MPa }\end{array}$ & 69000 & $2 . \mathrm{e}+005$ & $2.1 \mathrm{e}+005$ & $1 . \mathrm{e}-002$ \\
\hline Poisson's Ratio & 0.33 & 0.265 & 0.28 & 0.45 \\
\hline $\begin{array}{l}\text { Bulk Modulus } \\
\text { MPa }\end{array}$ & 67647 & $1.4184 \mathrm{e}+005$ & $1.5909 \mathrm{e}+005$ & $3.3333 \mathrm{e}-002$ \\
\hline $\begin{array}{l}\text { Shear Modulus } \\
\text { MPa }\end{array}$ & 25940 & 79051 & 82031 & $3.4483 \mathrm{e}-003$ \\
\hline Parts Assigned & $\begin{array}{l}\text { Aluminium Profile, } \\
\text { Angle brackets }\end{array}$ & $\begin{array}{l}\text { Ball screw, } \\
\text { Wheel rim }\end{array}$ & $\begin{array}{l}\text { Fork, Motor } \\
\text { housing, Earth } \\
\text { auger }\end{array}$ & Tyre \\
\hline
\end{tabular}

\section{Standard Earth gravity}

Structural analysis is performed by applying standard earth gravity load of $9806.6 \mathrm{~mm} / \mathrm{s}^{2}$ in the direction of $\mathrm{Y}$ (downward) with reference to coordinate frame the results of deformation and stress after solving the boundary conditions are given in Fig.4. 
(a)

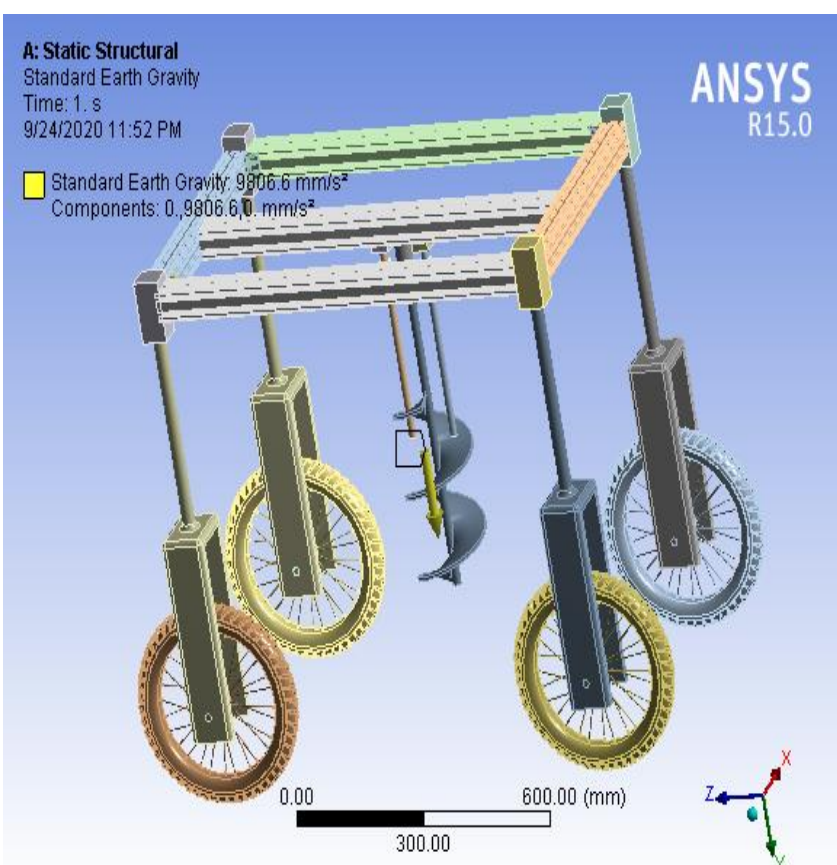

(d)

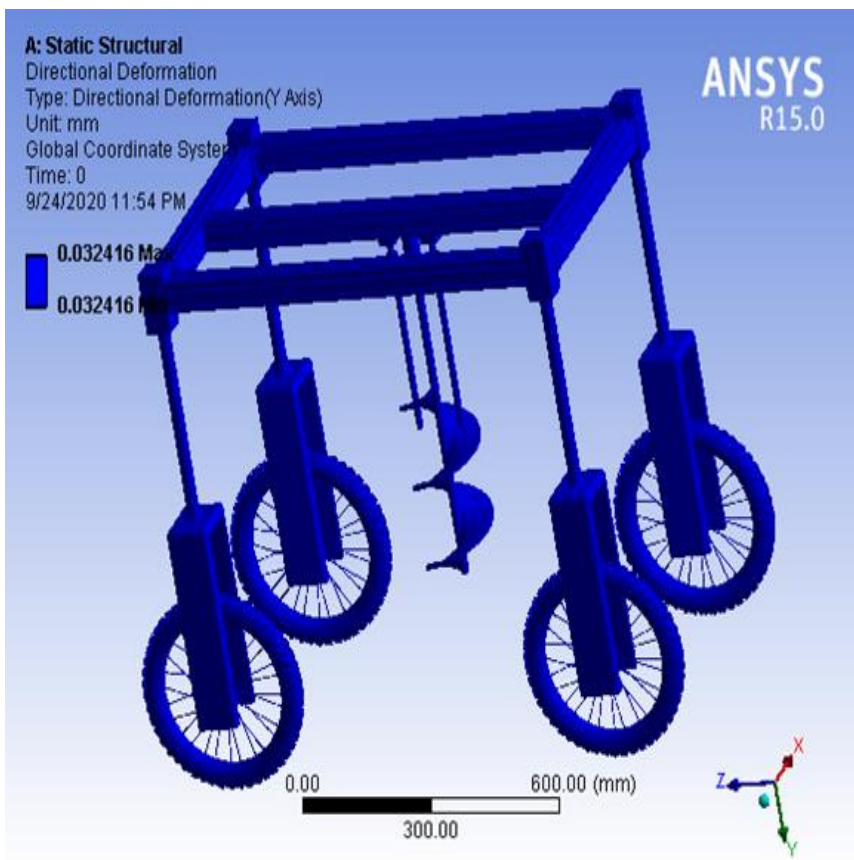

(b)

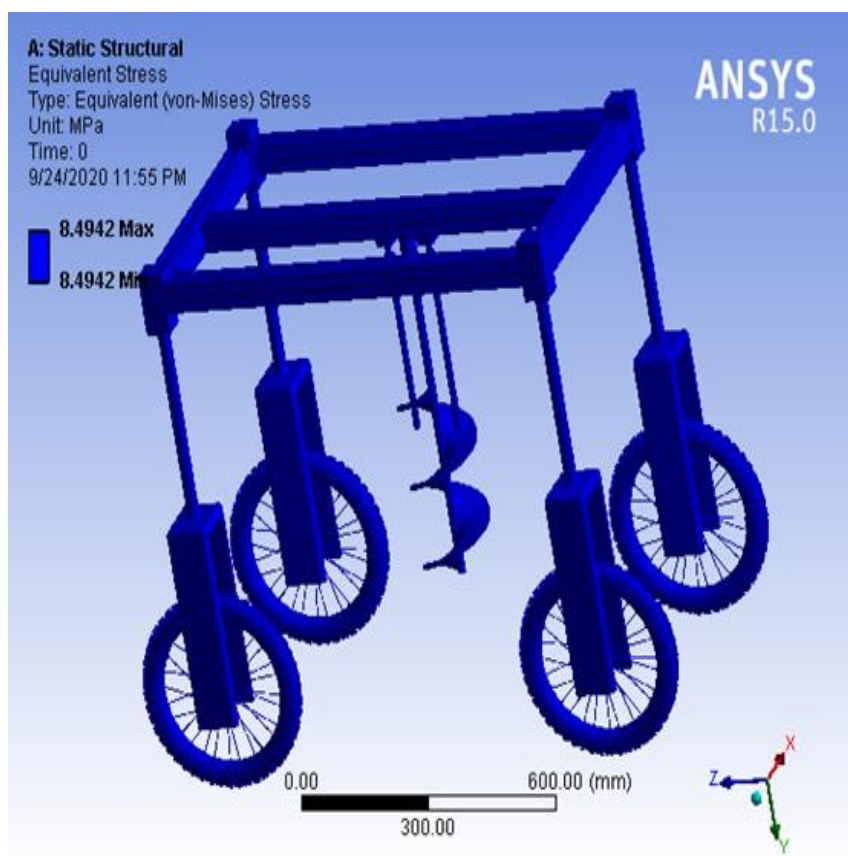

(c)

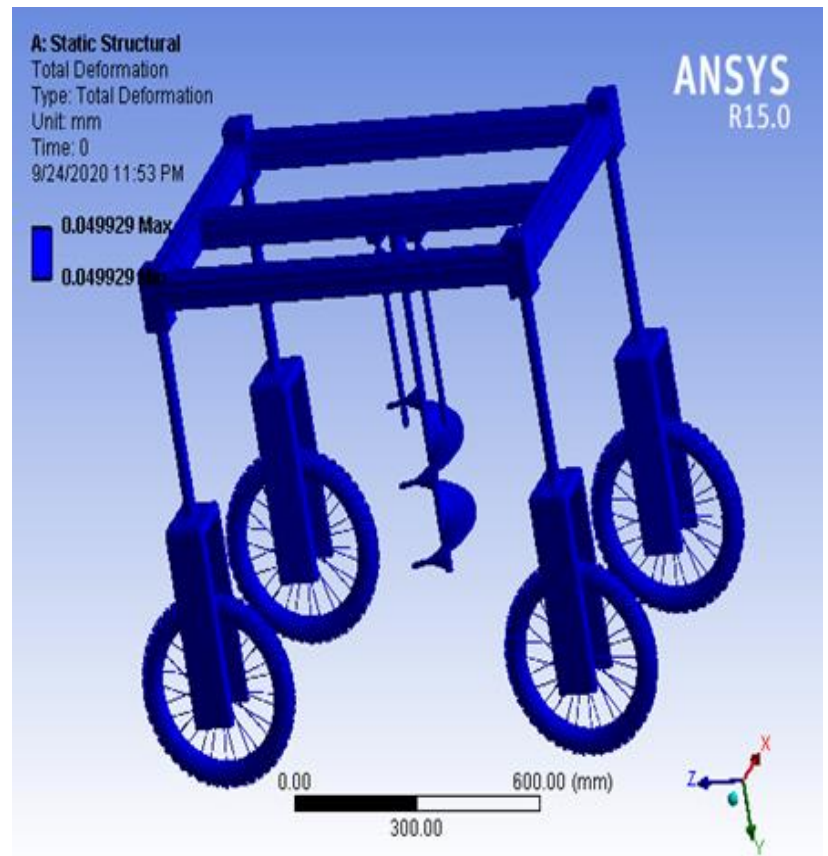

Figure 4 (a) Standard earth Gravity load (b) Equivalent stress (c) Directional deformation

(d) Total deformation 


\section{Structural Analysis with forces Applied}

Forces A,B,C,D with magnitude of $100 \mathrm{~N}$ each is applied at 4 different key points along the sections of aluminium profile, bottom faces of the fork is fixed. From the previous section it is

(a)

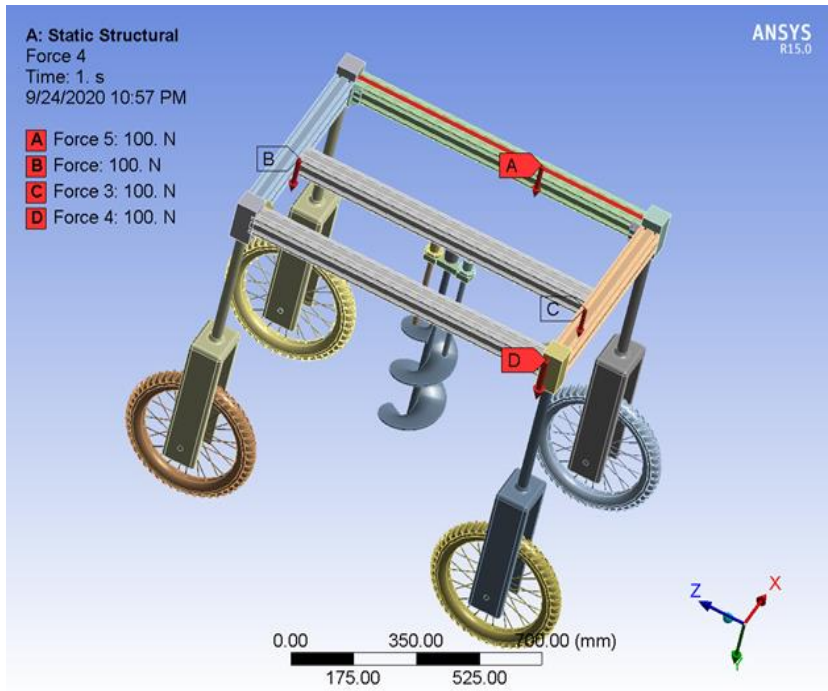

(c)

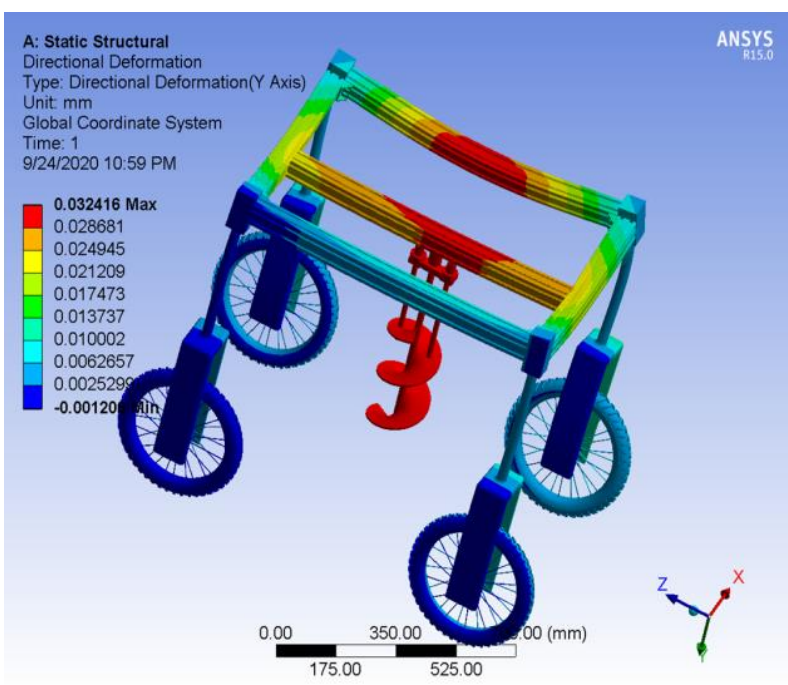

(b)

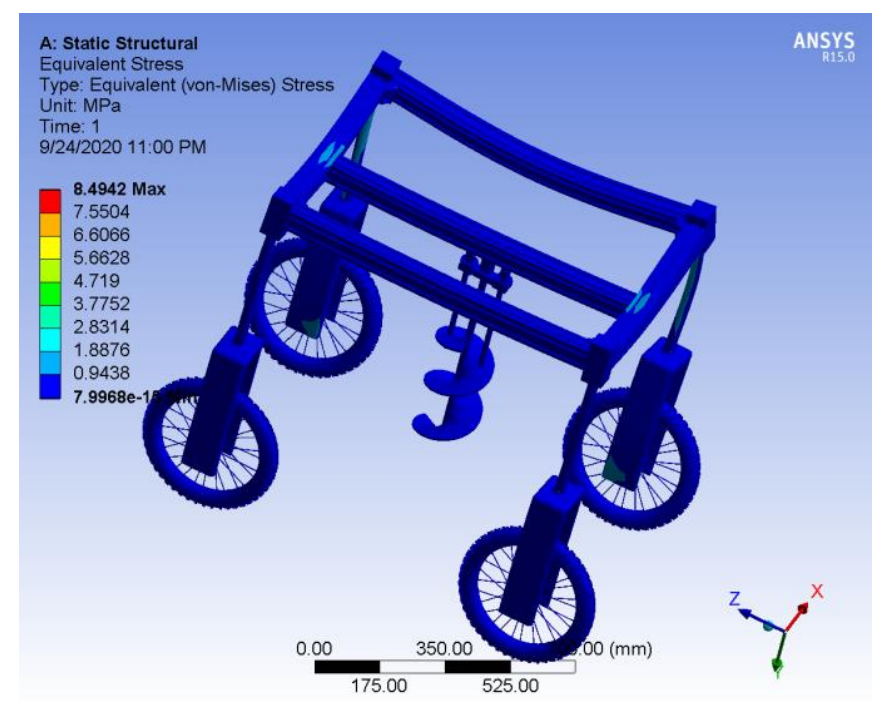

(d)

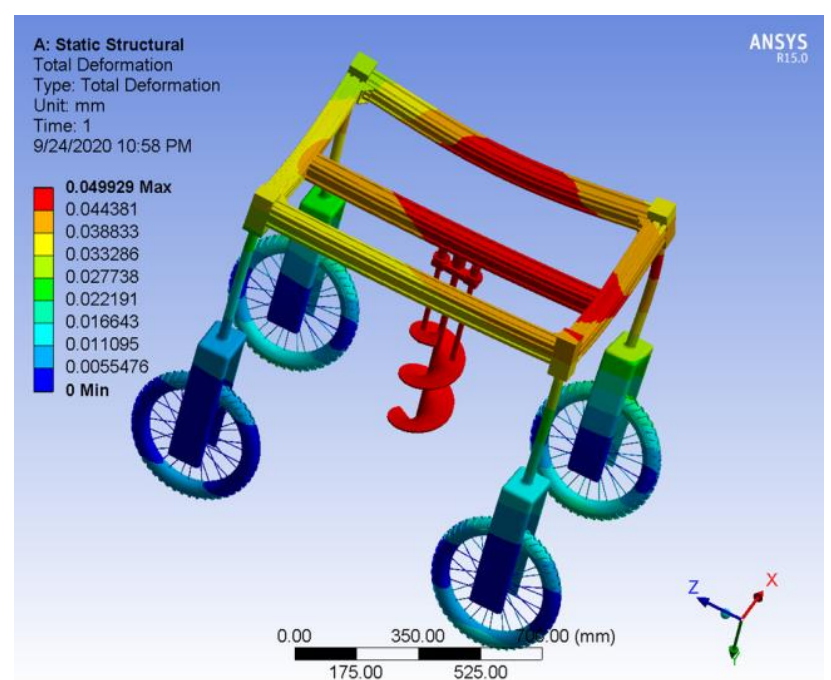

(c) Directional deformation 
inferred that standard earth gravity produced negligible deformation and stress hence, self weight of structural does not result in stress as well as deformation.

The reason for applying $100 \mathrm{~N}$ at key points is to compensate the load of battery and other electrical components to be fixed for operating the field robot. The response of the structure due to applied load is given in the Fig. $5 \sigma_{1}, \sigma_{2}, \sigma_{3}$ are stresses in perpendicular planes.

Von Mises stress, $\sigma_{V M}=\frac{\sqrt{\sigma_{1}-\sigma_{2}^{n}+\sigma_{2}-\sigma_{a}^{n}+\sigma_{a-} \sigma_{1}^{2}}}{2}$

Table 3 Comparison of results

\begin{tabular}{|c|c|c|c|c|c|c|}
\hline Parameter & \multicolumn{2}{|c|}{$\begin{array}{c}\text { Equivalent stress } \\
\text { (Mpa) }\end{array}$} & \multicolumn{2}{c|}{$\begin{array}{c}\text { Directional } \\
\text { Deformation (mm) }\end{array}$} & \multicolumn{2}{|c|}{$\begin{array}{c}\text { Total Deformation } \\
(\mathbf{m m})\end{array}$} \\
\hline $\begin{array}{c}\text { Loading } \\
\text { Condition }\end{array}$ & Min & Max & Min & Max & Min & Max \\
\hline $\begin{array}{c}\text { Standard } \\
\text { Earth } \\
\text { Gravity }\end{array}$ & 8.4942 & 8.4942 & 0.032416 & 0.032416 & 0.049929 & 0.049929 \\
\hline $\begin{array}{c}\text { External } \\
\text { Force }\end{array}$ & $7.9968 \mathrm{e}^{-15}$ & 8.4942 & -0.001206 & 0.032416 & 0 & 0.049929 \\
\hline
\end{tabular}

\section{CFD ANALYSIS}

Computational fluid dynamic (CFD) Analysis is performed to check the response of the field vehicle to open field wind conditions. In order to perform CFD analysis the model has to be converted into a full solid object without any assemblies or mate constraints following the topdown design methodology. The assembly equivalent of full solid model is given in the Fig.6.
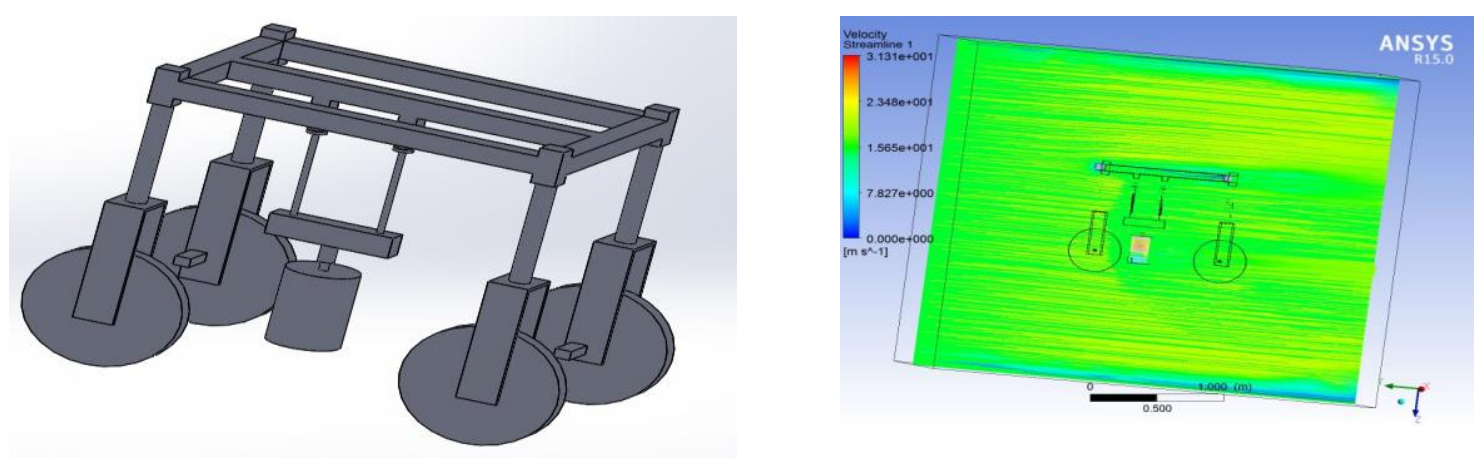
Figure 6 a) Full solid model for CFD Analysis b) Streamline of velocity
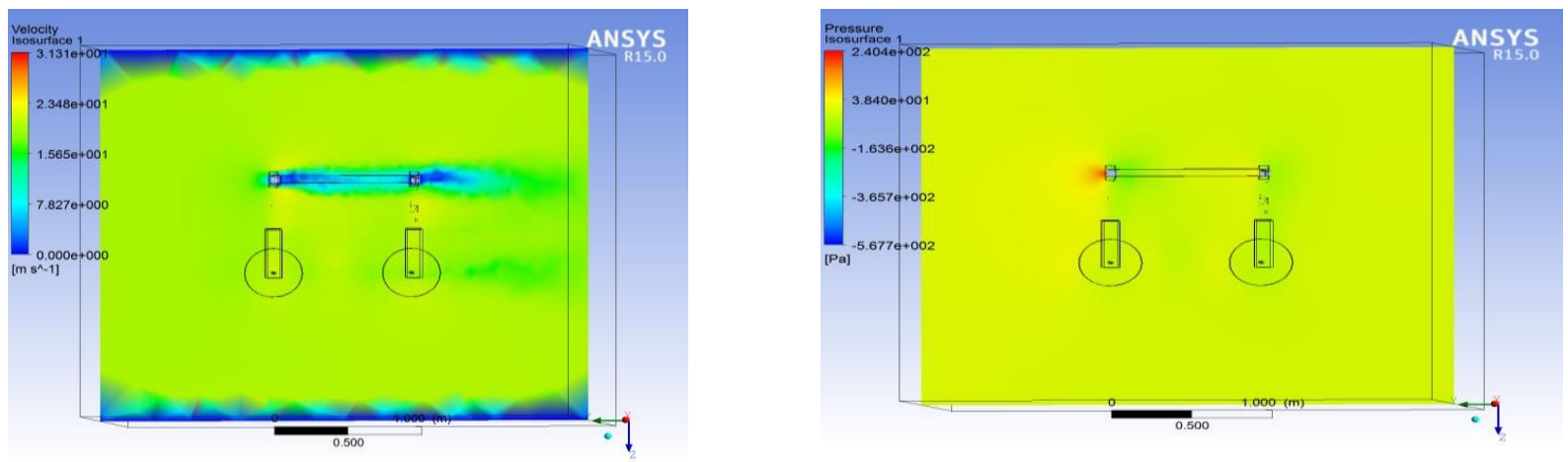

Figure 7 a) Isosurface of Velocity contour b) Isosurface of Pressure contour The inlet velocity is taken as $20 \mathrm{~m} / \mathrm{s}$ which is more than twice that of average wind conditions of open field i.e $9 \mathrm{~m} / \mathrm{s}$. The result is made to run for 200 iterations for converging.

\section{CONCLUSION}

This paper aims to describe about the CAD/CAE/CFD results of mobile manipulator conceptualized for Banana cultivation. The mechanical design is executed keeping in mind low cost, weight, manufacturability, modularity and simplicity. As far as possible standard elements are used in design, only the mechanical aspects of design are taken into account excluding the electronics associated with this field robot. The study has demonstrated the endurance of mechanical structure to loads and wind effects. Further research and study would be focused on gathering information about electronics and path planning. 


\section{REFERENCES}

Shah R, Ozcelik S and Challoo R., 2012. Design of a highly maneuverable mobile robot, Procedia Computer Science. 12, 170-175.

Anirudh Topiwala., 2016. Modeling and simulation of a differential drive mobile robot, International Journal of Scientific \& Engineering Research 7.

Bak T, Jakobsen H., 2004. Agricultural Robotic Platform with Four Wheels Steering for Weed Detection. Biosystems Engineering, London, v.87, n.2, 125-136.

Praveen D. Jadhav, Vijay Raghu S and Saifan Sab., 2016. Design and Fabrication of Crop

Analysis Agriculture Robot International Journal of Advanced Scientific Research and Management. 1, 19-22.

Bascetta, L., Baur, M. and Gruosso, G., 2017. ROBI': A prototype mobile manipulator for agricultural applications. Electronics, 6(2), 39.

Sharifi, M., Young, M.S., Chen, X., Clucas, D. and Pretty, C., 2016. Mechatronic design and development of a non-holonomic omnidirectional mobile robot for automation of primary production. Cogent Engineering, 3(1), 1250431.

Sakai S., Iida, M., Osuka, K. and Umeda, M., 2008. Design and control of a heavy material handling manipulator for agricultural robots. Autonomous Robots, 25(3), 189-204.

Tabile R.A., Godoy, E.P., Pereira, R.R., Tangerino, G.T., Porto, A.J. and Inamasu, R.Y., 2011. Design and development of the architecture of an agricultural mobile robot. Engenharia Agricola, 31(1), 130-142. 